\title{
Selection of a set of reliable reference genes for quantitative real-time PCR in normal equine skin and in equine sarcoids Lies Bogaert ${ }^{1}$, Mario Van Poucke ${ }^{2}$, Cindy De Baere ${ }^{1}$, Luc Peelman², Frank Gasthuys ${ }^{1}$ and Ann Martens*1
}

Address: ${ }^{1}$ Department of Surgery and Anaesthesiology of Domestic Animals, Faculty of Veterinary Medicine, Ghent University - UGent, Salisburylaan 133, B-9820 Merelbeke, Belgium and 2Department of Animal Nutrition, Genetics, Breeding and Ethology, Faculty of Veterinary Medicine, Ghent University - UGent, Heidestraat 19, B-9820 Merelbeke, Belgium

Email: Lies Bogaert - lies.bogaert@UGent.be; Mario Van Poucke - mario.vanpoucke@UGent.be; Cindy De Baere - cindy.debaere@UGent.be; Luc Peelman - luc.peelman@UGent.be; Frank Gasthuys - frank.gasthuys@UGent.be; Ann Martens* - ann.martens@UGent.be

* Corresponding author

Published: 27 April 2006

BMC Biotechnology 2006, 6:24 doi:10.1/86/1472-6750-6-24
Received: 19 December 2005

Accepted: 27 April 2006

This article is available from: http://www.biomedcentral.com/I472-6750/6/24

(c) 2006 Bogaert et al; licensee BioMed Central Ltd.

This is an Open Access article distributed under the terms of the Creative Commons Attribution License (http://creativecommons.org/licenses/by/2.0), which permits unrestricted use, distribution, and reproduction in any medium, provided the original work is properly cited.

\begin{abstract}
Background: Real-time quantitative PCR can be a very powerful and accurate technique to examine gene transcription patterns in different biological conditions. One of the critical steps in comparing transcription profiles is accurate normalisation. In most of the studies published on realtime PCR in horses, normalisation occurred against only one reference gene, usually GAPDH or $A C T B$, without validation of its expression stability. This might result in unreliable conclusions, because it has been demonstrated that the expression levels of so called "housekeeping genes" may vary considerably in different tissues, cell types or disease stages, particularly in clinical samples associated with malignant disease. The goal of this study was to establish a reliable set of reference genes for studies concerning normal equine skin and equine sarcoids, which are the most common skin tumour in horses.

Results: In the present study the gene transcription levels of 6 commonly used reference genes (ACTB, B2M, HPRTI, UBB, TUBA I and RPL32) were determined in normal equine skin and in equine sarcoids. After applying the geNorm applet to this set of genes, TUBA I, ACTB and UBB were found to be most stable in normal skin and $B 2 M, A C T B$ and $U B B$ in equine sarcoids.

Conclusion: Based on these results, TUBAI, ACTB and UBB, respectively B2M, ACTB and UBB can be proposed as reference gene panels for accurate normalisation of quantitative data for normal equine skin, respectively equine sarcoids. When normal skin and equine sarcoids are compared, the use of the geometric mean of UBB, ACTB and B2M can be recommended as a reliable and accurate normalisation factor.
\end{abstract}

\section{Background}

Gene expression analysis has become increasingly important in biological research where e.g. gene expression profiles from tissues associated with diseases and disorders have to be compared with each other and with those from normal tissues. One of the most powerful tools in this area is real-time quantitative reverse transcription PCR (qRT-PCR). To account for differences in starting material, RNA preparation, RNA quality and CDNA synthesis, adequate normalisation is frequently performed by compar- 
ing expression profiles of the genes of interest with those of constitutively expressed genes (= reference genes). Housekeeping genes are most widely used as reference genes, based on the assumption that they are constitutively expressed in most tissues and under certain circumstances, and that they are more or less resistant to cell cycle fluctuations $[1,2]$. However, it has been demonstrated that the expression levels of these genes may vary considerably in different tissues, different cell types and different disease stages, particularly in clinical samples associated with malignant disease $[3,4]$. Housekeeping genes are not only involved in the basal cell metabolism, but appear to participate in other functions too, and therefore are prone to regulation [5-7]. Especially in tumours, the metabolism is generally elevated because of permanent proliferation and expansion. Moreover, some housekeeping genes may have a specific function essential for the tumour metabolism and therefore be up or down regulated [8]. Because of these findings, Vandesompele et al [9] proposed to identify a set of stable housekeeping genes in the tissue of interest and use them as internal reference genes for accurate normalisation.

Up till now, only a few gene expression studies using realtime qRT-PCR have been performed in horses. GAPDH or $A C T B$ were commonly used as a single non-validated reference gene [10-15], since at that time not much information was available concerning this issue. Recently, Waguespack et al [16] compared 4 housekeeping genes (ACTB, B2M, GAPDH and TBP) in the lamellae of the hoof in horses.

In this study, 6 commonly used reference genes in both human and animal studies were investigated, both in normal skin and in equine sarcoids of horses. Equine sarcoids are fibroblastic skin tumours and are the most common tumours in horses. The disease not only induces esthetical defects, but also diminishes the economical value of affected horses [17]. Moreover affected horses show a genetic predisposition for the development of equine sarcoids, through which the breeding value of an animal with sarcoids sharply declines [18-20]. The bovine papillomavirus (BPV) plays an important role in the aetiology of equine sarcoids [21-23]. Several clinical types exist, ranging from small, stable patches to large, aggressive and fast growing tumours [24]. To be able to examine the gene expression profile of BPV in these different clinical types and to compare equine sarcoids with normal skin asymptomatically infected with BPV, a well suited internal control should first of all be established.

\section{Results and discussion Transcription profiling of the candidate genes}

cDNA was synthesised from DNA-free RNA (checked with minus RT control) isolated from 8 normal equine skin and 8 equine sarcoid samples. A real-time PCR assay, based on SYBR ${ }^{\circledast}$ Green detection, was designed for the transcription profiling of six frequently used reference genes (ACTB, B2M, HPRT1, UBB, TUBA1 and RPL32 )in these cDNA samples. During optimisation of the protocol, real-time PCR products were visualised by gelelectrophoresis and sequenced for verification. For every assay, a single amplicon with the expected size was generated without primer dimer formation. Indeed, the formation of primer dimers and unspecific amplification, which can falsely increase the gene expression levels, is a major point of attention, particularly when using intercalating dyes such as SYBR $^{\circledast}$ Green.

Amplicon sequences of ACTB, B2M, HPRT1, and TUBA1 were $100 \%$ identical with the described sequences on which primer design was based. The sequencing of $U B B$ revealed 1 gap and 3 SNPs compared to the original sequence ( $98 \%$ identity). The gap is probably due to sequencing errors; the SNPs did not result in an amino acid variation. When translated to amino acid sequence, the RPL32 sequence was $100 \%$ identical to publicly accessible horse ESTs and human RPL32 amino acid sequences.

After optimisation, gene-specific amplification was confirmed by a single peak in melt-curve analysis. For each assay, a standard curve was generated by using 10 -fold serial dilutions of pooled cDNA, generated of both normal skin and equine sarcoid tissue, characterised by a linear correlation coefficient $\left(\mathrm{R}^{2}\right)$ varying from 0.991 to 0.998 and a PCR efficiency between 88.1 and $104.6 \%$. These findings showed that these assays are suitable for quantitative purposes.

In order to select a reliable set of reference genes, each assay was performed in duplicate and included the appropriate control samples. To compare the transcription level of the selected genes across the different samples, the $\mathrm{Ct}$ values, ranging from 16.4 to 31.4 were converted into raw data based on the PCR efficiency, gathered by standard curve analyses.

\section{GeNorm analysis}

The gene expression stability over the different samples was analysed using the geNorm software [9]. The ranking of the 6 candidate reference genes according to their $M$ value was not equivalent between the normal skin samples, the equine sarcoid samples and the combination of both kinds of samples. For normal skin ACTB, TUBA1 and $U B B$ were the 3 most stable genes (Figure $1 \mathrm{~A}(\mathrm{a})$ ). In equine sarcoids on the other hand, $A C T B, B 2 M$ and $U B B$ proved to be the most stable genes with TUBA1 being the least stable gene (Figure 1B(a)). When both sets of samples were analysed together, the results showed that the combination of 3 genes ( $A C T B, U B B$ and $B 2 M$ ) is suffi- 
Figure $1 \mathrm{~A}(\mathrm{a})$

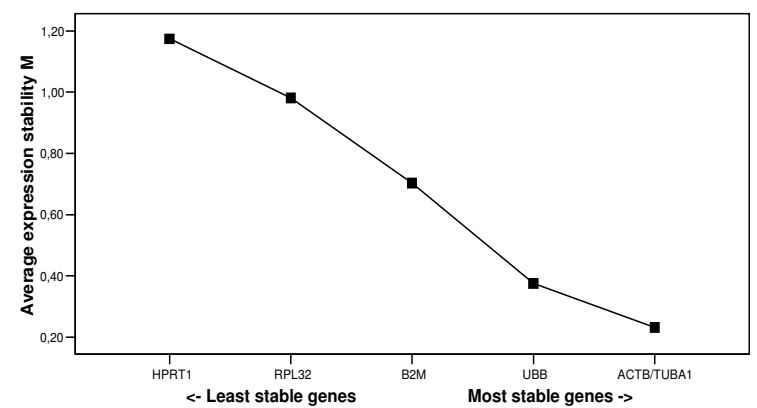

Figure 1B(a)

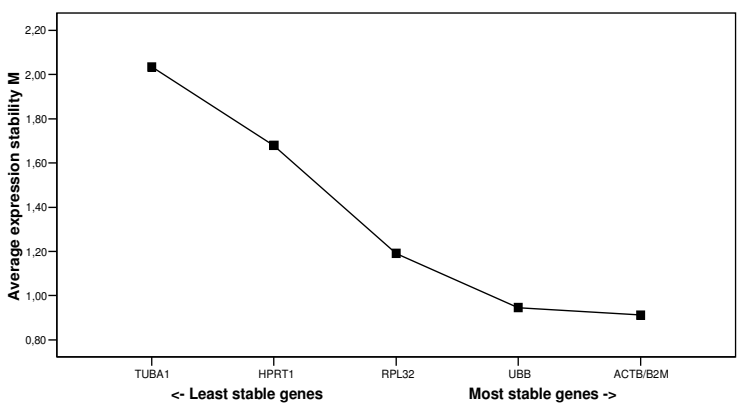

Figure $1 \mathrm{C}(\mathrm{a})$

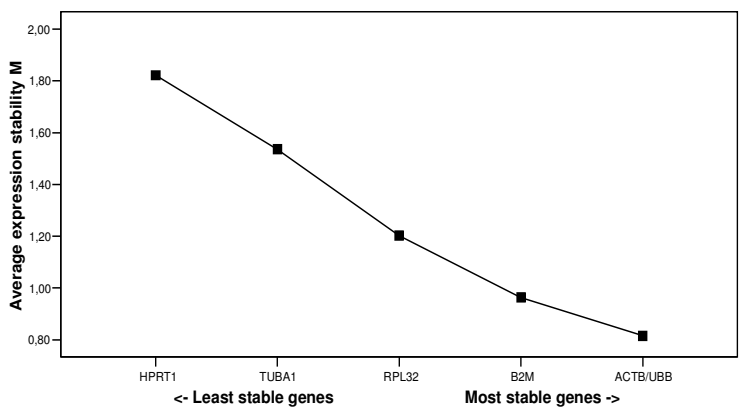

Figure $1 \mathrm{~A}(\mathrm{~b})$

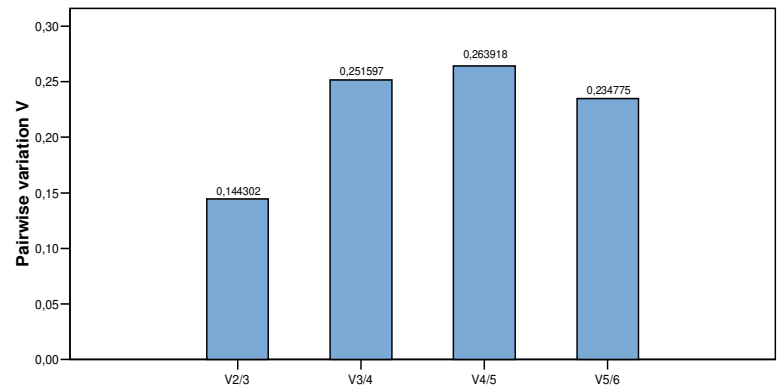

Figure $1 \mathrm{~B}(\mathrm{~b})$

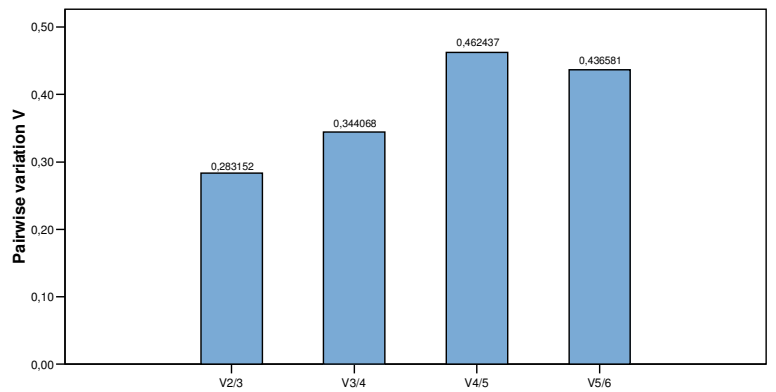

Figure $1 \mathrm{C}(\mathrm{b})$

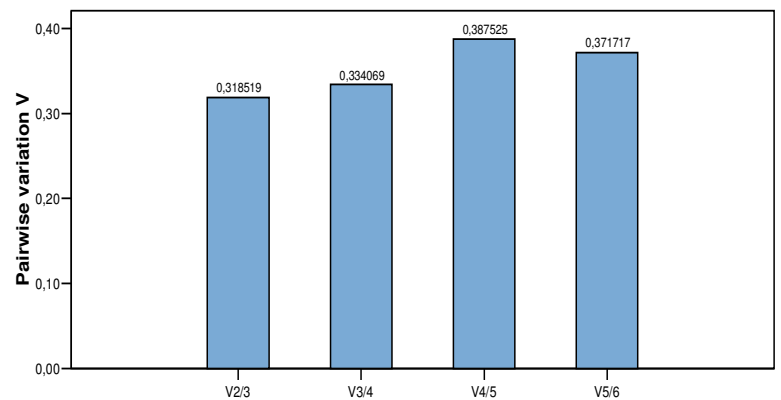

\section{Figure I}

Gene expression stability of the 6 candidate reference genes analysed by the geNorm program [9]. (a) Average expression stability values $(M)$ of the control genes, plotted from least stable (left) to most stable (right). (b) Pairwise variation analysis between the normalisation factors $\mathrm{NF}_{\mathrm{n}}$ and $\mathrm{NF}_{\mathrm{n}+1}$, to determine the optimal number of control genes for normalisation. The higher $V_{3 / 4}$ value is due to the inclusion of a relative unstable gene and is in accordance with the average expression stability M. A - Normal skin. B - Equine sarcoids. C - Combination of normal skin and equine sarcoids. 
Table I: Ranking of the reference genes. The reference genes are ranked in order of their expression stability in normal equine skin, in equine sarcoids and in the combination of both kinds of samples, decreasing from top to bottom. The reference genes chosen to calculate the normalisation factor, used for comparing equine sarcoids and normal skin, are printed in bold.

\begin{tabular}{lll}
\hline Normal skin & Equine sarcoid & Combination \\
\hline TUBAI & B2M & UBB \\
ACTB & ACTB & ACTB \\
UBB & UBB & B2M \\
B2M & RPL32 & RPL32 \\
RPL32 & HPRTI & TUBAI \\
HPRTI & TUBAI & HPRTI \\
\hline
\end{tabular}

cient for adequate normalisation (Figure 1C(a)). The results are listed in Table 1 . In another study [16], where $A C T B, B 2 M$, GAPDH and TBP were compared as reference genes, $A C T B$ and $B 2 M$ were found to be the best endogenous control genes for real-time qPCR of lamella in the hoof of horses.

When calculating a normalisation factor (NF), a careful choice of the number of reference genes should be made. The more genes included, the more accurate the NF is. However, including too many genes may increase the risk of using unsuitable genes, and is also impractical. On the other hand, if the cut off is made too stringent, stably expressed reference genes may be excluded and accuracy might drop. In order to determine how many reference genes should be included, normalisation factors $\left(\mathrm{NF}_{\mathrm{n}}\right)$, based on the geometric mean of the expression levels of the $\mathrm{n}$ best reference genes, were calculated by inclusion of an extra, less stable, reference gene according to Vandesompele et al [9]. Figures $1 \mathrm{~A}(\mathrm{~b}), 1 \mathrm{~B}(\mathrm{~b})$ and $1 \mathrm{C}(\mathrm{b})$ show the pairwise variation $V_{n} / V_{n+1}$ between 2 sequential normalisation factors $\mathrm{NF}_{n}$ and $\mathrm{NF}_{n+1}$ for normal skin, equine sarcoids and the combination of both kinds of samples. In all 3 cases, the inclusion of a $4^{\text {th }}$ gene had no significant contribution (low $\mathrm{V}_{3 / 4}$ value) to the NF. The 3 member sets as described above are a good choice for the calculation of the NF.

\section{Implementation of results in clinical research}

For the reasons discussed above, we have confidence that our gene expression results are accurate and reliable. The described set of reference genes can be used in gene expression studies both in normal skin, equine sarcoids and the combination of both. One of the points of interest in veterinary medicine is the expression level of BPV in different kinds of equine sarcoids. With the normalisation technique described in this study, reliable results can be obtained. Another research topic in this domain is the study of BPV expression in normal skin, showing latent infection with BPV. Also, the expression level of specific horse genes with a putative role in tumourigenesis, can be investigated.

\section{Conclusion}

In conclusion, a method for genomic DNA-free RNA extraction from normal equine skin and equine sarcoids was optimised and a reference gene assay for reliable normalisation of real-time qPCR data, obtained from normal skin, equine sarcoids and the combination of both, was designed. The profiling of the gene expression pattern of 6 putative reference genes showed that 3 reference genes should be used. $A C T B, T U B A 1$ and $U B B$ can be used in normal skin, while $A C T B, B 2 M$ and $U B B$ are the best choice in equine sarcoids. If normal skin and equine sarcoids have to be compared, the same member set as proposed for equine sarcoids can be used.

\section{Methods \\ Sample collection}

Eight equine sarcoid samples were obtained from surgically treated horses. A whole range of tumours were sampled (one occult type, one verrucous type, one nodular type and five fibroblastic types). Three sarcoids were located on the medial part of the thigh, two in the axilla and two on the ventral side of the abdomen. Care was taken to obtain only tumoural tissue, without underlying normal stroma. Normal skin samples were obtained from healthy horses undergoing elective surgery or euthanasia (umbilical hernia, castration, osteochondrosis dissecans, dorsal displacement of the soft palatinum). Six of the samples were collected from the ventral abdomen, one from the throat region and one from the shoulder. All samples were freshly collected and stored immediately in RNAlater (Ambion). After overnight incubation at $+4^{\circ} \mathrm{C}$, the samples were frozen at $-18^{\circ} \mathrm{C}$ until RNA extraction.

\section{RNA extraction and CDNA synthesis}

Total RNA was isolated from the samples using TRIR (ABgene) according to the manufacturer's instructions. Subsequently, approximately $4 \mu \mathrm{g}$ of the total RNA solution, measured with the BioPhotometer (Eppendorf), were treated with 3 units DNase I (Ambion) to remove genomic DNA. This was followed by a spin-column purification (Microcon YM-10, Millipore). A minus RT control with primers for GAPDH was performed to check for successful removal of all the contaminating DNA. These primers were designed by the Primer 3 software [25] using publicly available sequences from the Nucleotide Sequence Database from the National Center for Biotechnology Information (NCBI) [26]. The initial denaturation was performed at $94^{\circ} \mathrm{C}$ for 10 minutes. Thirty-five cycles of amplification were performed. Each cycle involved a denaturation step of 30 seconds at $94^{\circ} \mathrm{C}$, followed by 30 seconds primer annealing at $61^{\circ} \mathrm{C}$ and 60 seconds primer extension at $72{ }^{\circ} \mathrm{C}$. After the last cycle, the PCR-mix was 
Table 2: Name and function of genes mentioned in the text

\begin{tabular}{lll}
\hline Symbol* & Gene name* & Function \\
\hline ACTB & actin, beta & Cytoskeletal structural protein \\
B2M & beta-2-microglobulin & Beta-chain of major histocompatibility complex class I molecules \\
HPRTI & hypoxanthine phosphoribosyltransferase I & Purine synthesis in salvage pathway \\
UBB & ubiquitin B & Protein degradation \\
TUBAI & tubulin, alpha I (testis specific) & Structural protein \\
RPL32 & ribosomal protein L32 & Member of the 80 different ribosome proteins \\
GAPDH & glyceraldehyde-3-phosphate dehydrogenase & Glycolytic enzyme \\
TBP & TATA box binding protein & General RNA polymerase II transcription factor \\
\hline
\end{tabular}

* Nomenclature according to Genew [28]

heated during 10 minutes at $72^{\circ} \mathrm{C}$ to become extension of the partially elongated primers.

First strand cDNA synthesis was carried out on approximately $2.6 \mu \mathrm{g}$ of the total RNA solution with Superscript ${ }^{\mathrm{TM}}$ II Reverse Transcriptase (Invitrogen), an engineered version of M-MLV RT, and a combination of random primers (Invitrogen) and oligo(dT)20 primers (Invitrogen) in a total volume of $20 \mu \mathrm{l}$, following the manufacturer's instructions. After this step, a PCR was performed with primers for GAPDH to check for the presence of cDNA. The reaction conditions used in this PCR were identical to the PCR described for the minus RT control.

\section{Reference gene selection and primer design}

Six reference genes $(A C T B, B 2 M, H P R T 1, U B B, T U B A 1$ and RPL32) belonging to different functional classes were selected to reduce the chance that these genes might be coregulated (Table 2 ).

The primers, based on horse RNA and DNA sequences found in the NCBI database [26], were designed by the Primer 3 software [25]. The specificity of the primers was tested using a BLAST analysis against the genomic NCBI database. The complete nucleotide sequences of the genes of interest were characterised using Mfold [27] to take into account possible secondary structures at the primer binding sites which might influence the PCR efficiency. The PCR products were cloned (pCR 2.1 vector, Invitrogen) and sequenced for verification (Thermo Sequenase Primer Cycle Sequencing Kit, Amersham Bioscience) with an ALF Express sequencer (Amersham Bioscience). Technical information about the primers and amplicons are listed in Table 3.

\section{Real-time quantitative PCR}

Eight normal skin samples and eight equine sarcoid samples were used for quantification of reference genes.

PCR reactions were performed in a $15 \mu$ reaction volume on the iCycler iQ Real-Time PCR Detection System (BioRad) using the Platinum ${ }^{\circledast}$ SYBR $^{\circledast}$ Green qPCR SuperMix UDG (Invitrogen) supplemented with $0.02 \mu \mathrm{M}$ fluorescein and $20 \mathrm{ng}$ of cDNA. Primer concentration varied according to the primers used. A blank was incorporated in each assay.

Table 3: Information on the primers used in this study

\begin{tabular}{|c|c|c|c|c|c|}
\hline Gene & Genbank accession number & Primer sequence & $\operatorname{Ta}\left({ }^{\circ} \mathrm{C}\right)$ & Product size (bp) & Primer concentration \\
\hline ACTB & AF035774 & $\begin{array}{l}\text { CCAGCACGATGAAGATCAAG } \\
\text { GTGGACAATGAGGCCAGAAT }\end{array}$ & 59 & 88 & $\begin{array}{l}0.5 \mu \mathrm{l} \\
10 \mu \mathrm{M}\end{array}$ \\
\hline$B 2 M$ & $\underline{X 69083}$ & $\begin{array}{l}\text { GTTCCATCCGCCTGGAGATT } \\
\text { GGGGGTCTTTGAGAGTAGAGTG }\end{array}$ & 60 & 182 & $\begin{array}{l}0.25 \mu \mathrm{l} \\
10 \mu \mathrm{M}\end{array}$ \\
\hline HPRTI & AY372182 & $\begin{array}{l}\text { GGCAAAACAATGCAAACCTT } \\
\text { CAAGGGCATATCCTACGACAA }\end{array}$ & 60 & 163 & $\begin{array}{l}0.5 \mu \mathrm{l} \\
10 \mu \mathrm{M}\end{array}$ \\
\hline UBB & AF506969 & $\begin{array}{l}\text { GCAAGACCATCACCCTGGA } \\
\text { CTAACAGCCACCCCTGAGAC }\end{array}$ & 61 & 206 & $\begin{array}{l}0.5 \mu \mathrm{l} \\
10 \mu \mathrm{M}\end{array}$ \\
\hline TUBAI & AW260995 & $\begin{array}{l}\text { GCCCTACAACTCCATCCTGA } \\
\text { ATGGCTTCATTGTCCACCA }\end{array}$ & 60 & 78 & $\begin{array}{l}0.5 \mu \mathrm{l} \\
10 \mu \mathrm{M}\end{array}$ \\
\hline RPL32 & CX594263 & $\begin{array}{l}\text { AGCCATCTACTCGGCGTCA } \\
\text { TCCAATGCCTCTGGGTTTC }\end{array}$ & 61 & 149 & $\begin{array}{l}0.25 \mu \mathrm{l} \\
\mathrm{I} 0 \mu \mathrm{M}\end{array}$ \\
\hline GAPDH & $\underline{A F I 57626}$ & $\begin{array}{l}\text { GATGCCCCAATGTTTGTGA } \\
\text { AAGCAGGGATGATGTTCTGG }\end{array}$ & 61 & 250 & $\begin{array}{l}0.5 \mu \mathrm{l} \\
10 \mu \mathrm{M}\end{array}$ \\
\hline
\end{tabular}


First, an UDG-treatment was done at $50^{\circ} \mathrm{C}$ to prevent cross contamination. The initial denaturation was performed at $95^{\circ} \mathrm{C}$ for 2 minutes to activate the Taq DNA polymerase, followed by 40 cycles of denaturation at $95^{\circ} \mathrm{C}$ for 20 seconds and a combined primer annealing/ extension at the specific annealing temperature (Table 3 ) for 40 seconds during which fluorescence was measured. A melt curve was generated to confirm a single gene-specific peak and to detect primer dimer formation by heating the samples from 70 to $95^{\circ} \mathrm{C}$ in $0.5^{\circ} \mathrm{C}$ increments with a dwell time at each temperature of 10 seconds while continuously monitoring the fluorescence.

PCR efficiencies were calculated using a relative standard curve derived from a pooled cDNA mixture (a ten-fold dilution series with four measuring points). The pooled cDNA was obtained from normal equine skin and equine sarcoids, using the same RNA isolation and cDNA synthesis protocols as described above.

Each reaction was run in duplicate, whereby a no-template control was included.

During optimisation of the protocol, the PCR products were loaded on a 3\% agarose gel after each run to confirm specific gene amplification and the absence of primer dimer formation.

\section{Determination of reference gene expression stability}

To determine the stability of the selected reference genes, the geNorm Visual Basic application for Microsoft Excel was used as described by Vandesompele et al [9]. This approach relies on the principle that the expression ratio of two perfect reference genes should be identical in all samples, independent of the experimental condition or cell type.

\section{Authors' contributions}

LB was the primary author of the manuscript, was responsible for the primer design and determined the study design. MVP participated in the study design and provided real-time support. $\mathrm{CDB}$ performed most of the experimental procedures. LP, AM and FG participated in the design of the project, helped to draft the manuscript and supervised the study. All authors read and approved the final manuscript.

\section{Acknowledgements}

This research was funded by the Special Research Fund, Ghent University, grant no. OIDOII03.

\section{References}

I. Radonic A, Thulke S, Bae HG, Müller MA, Siegert W, Nitsche A: Reference gene selection for quantitative real-time PCR analysis in virus infected cells: SARS corona virus, Yellow fever virus, Human Herpesvirus-6 and Cytomegalovirus infections. Virol J 2005, 2:7.
2. Zhang $X$, Ding L, Sandford A]: Selection of reference genes for gene expression studies in human neutrophils by real-time PCR. BMC Mol Biol 2005, 6:4.

3. Thellin O, Zorzi W, Lakaye B, De Borman B, Coumans B, Hennen G, Gristar T, lgout $A$, Heinen $E$ : Housekeeping genes as internal standards: use and limits. J Biotechnol 1999, 75:29I-295.

4. Suzuki T, Higgins PJ, Crawford DR: Control selection for RNA quantitation. Biotechniques 2000, 29:332-337.

5. Petersen BH, Rapaport F, Henry DP, Huseman C, Moore DP: Effect of treatment with biosynthetic human growth hormone (GH) on peripheral blood lymphocyte populations and function in growth hormone-deficient children. J Clin Endocrinol Metab 1990, 70:1756-1760.

6. Singh R, Green MR: Sequence specific binding of transfer RNA by glyceraldehydes-3-phosphate dehydrogenase. Science 1993, 259:365-368.

7. Ishitani R, Sunaga K, Hirano A, Saunders P, Katsube N, Chang DM: Evidence that glyceraldehydes-3-phosphate dehydrogenase is involved in age-induced apoptosis in mature cerebellar neurons in culture. I Neurochem 1996, 66:928-935.

8. Neuvians TP, Gashaw I, Sauer CG, von Ostau C, Kliesch S, Bergmann M, Häcker A, Grobholz R: Standardization strategy for quantitative PCR in human seminoma and normal testis. J Biotechnol 2005, II 7:163-17|.

9. Vandesompele J, De Preter K, Pattyn F, Poppe B, Van Roy N, De Paepe A, Speleman F: Accurate normalization of Real-Time quantitative RT-PCR by geometric averaging of multiple internal control genes. Genome Biol 2002, 3:34 [http:// medgen.ugent.be/ jvdesomp/genorm/].

10. Giguère $S$, Prescott JF: Quantitation of equine cytokine mRNA expression by reverse transcription-competitive polymerase chain reaction. Vet Immunol Immunop 1999, 67: I-I5.

II. Leutenegger CM, von Rechenberg B, Huder JB, Zlinsky K, Mislin C, Akens MK, Auer J, Lutz H: Quantitative real-time PCR for equine cytokine mRNA in nondecalcified bone tissue embedded in methyl methacrylate. Calcif Tissue Int 1999, 65:378-383.

12. Swiderski C, Klei TR, Horohov DW: Quantitative measurement of equine cytokine mRNA expression by polymerase chain reaction using target-specific standard curves. J Immunol Methods 1999, 222:155-169.

13. von Rechenberg B, Leutenegger C, Zlinsky K, Mcllwraith CW, Akens MK, Auer JA: Upregulation of mRNA of interleukin- $I$ and -6 in subchondral cystic lesions of four horses. Equine Vet J $200 \mathrm{I}$, 33:143-149.

14. Ainsworth DM, Appleton JA, Eicker SW, Luce R, Flaminio MJ, Antzack DF: The effect of strenuous exercise on mRNA concentrations of interleukin-12, interferon-gamma and interleukin-4 in equine pulmonary and peripheral blood mononuclear cells. Vet Immunol Immunop 2003, 9 I:6I-7I.

15. Lim WS, Edwards JF, Boyd NK, Payne SL, Ball JM: Simultaneous quantitation of equine cytokine mRNAs using a multi-probe ribonuclease protection assay. Vet Immunol Immunop 2003, $91: 45-51$.

16. Waguespack RW, Kemppainen RJ, Cochran A, Lin HC, Belknap JK: Increased expression of MAIL, a cytokine-associated nuclear protein, in the prodromal stage of black walnut-induced laminitis. Equine Vet J 2004, 36:285-291.

17. Gerber $\mathrm{H}$ : The genetic basis of some equine diseases. Equine Vet J 1989, 21:244-248.

18. Lazary S, Gerber H, Glatt PA, Straub R: Equine leucocyte antigens in sarcoid-affected horses. Equine Vet J 1985, 17:283-286.

19. Meredith D, Elser AH, Wolf B, Soma LR, Donawick WJ, Lazary F: Equine Leucocyte Antigens: relationships with sarcoid tumors and laminitis in two pure breeds. Immunogenetics 1986, 23:22I-225.

20. Gerber H, Dubath M-L, Lazary S: Association between predisposition to equine sarcoid and MHC in multiple-case families. In Proceedings of the 5th International Conference on Equine Infectious Diseases Edited by: Powell DG. The University Press of Kentucky; 1988:272-277.

21. Otten N, von Tscharner C, Lazary S, Antczak DF, Gerber H: DNA of bovine papillomavirus type $I$ and 2 in equine sarcoids: PCR detection and direct sequencing. Arch Virol 1993, 132:|2|-|3|.

22. Teifke JP, Hardt M, Weiss E: Detection of bovine papillomavirus DNA in formalin-fixed and paraffin-embedded equine sar- 
coids by polymerase chain reaction and non-radioactive in situ hybridization. European Journal of Veterinary Pathology 1994, I:5-10.

23. Nasir L, Reid SW]: Bovine papillomaviral gene expression in equine sarcoid tumours. Virus Res 1999, 61:171-175.

24. Pascoe RR, Knottenbelt DC: Neoplastic conditions. In Manual of equine dermatology Edited by: Pascoe RR, Knottenbelt DC. London: Saunders; 1999:244-252.

25. Rozen S, Skaletsky HJ: Primer3 on the WWW for general users and for biologist programmers. Bioinformatics Methods and Protocols: Methods in Molecular Biology 2000:365-386 [http:// frodo.wi.mit.edu/cgi-bin/primer3/primer3 www.cgi]. Totowa, NJ: Humana Press

26. National Center for Biotechnology Information [http://
[ www3.ncbi.nlm.nih.gov/]

27. Zuker M: Mfold web server for nucleic acid folding and hybridization prediction. Nucleic Acids Res 2003, 31:3406-3415 [http:// www.bioinfo.rpi.edu/applications/mfold/old/dna/forml.cgi].

28. Wain HM, Bruford EA, Lovering RC, Lush MJ, Wright MW, Povey S: Guidelines for Human Gene Nomenclature. Genomics 2002, 79:464-470 [http://www.gene.ucl.ac.uk/cgi-bin/nomenclature/search genes.pl].

Publish with Bio Med Central and every scientist can read your work free of charge

"BioMed Central will be the most significant development for disseminating the results of biomedical research in our lifetime. "

Sir Paul Nurse, Cancer Research UK

Your research papers will be:

- available free of charge to the entire biomedical community

- peer reviewed and published immediately upon acceptance

- cited in PubMed and archived on PubMed Central

- yours - you keep the copyright

Submit your manuscript here:

http://www.biomedcentral.com/info/publishing_adv.asp 